\title{
Nuclear medicine impact on differentiated thyroid cancer diagnosis and treatment
}

\author{
Sevastián Medina-Ornelas, ${ }^{1}$ Francisco García-Pérez ${ }^{1}$ and Martín Granados-García
}

${ }^{1}$ Department of Nuclear Medicine and Molecular Imaging; '2Department of Head and Neck Surgery, Secretaría de Salud, Instituto Nacional de Cancerología, Ciudad de México, Mexico

\begin{abstract}
Patients affected by differentiated thyroid cancer usually have a favorable clinical course, since the cornerstone of treatment is surgery; despite this, some patients may develop an ominous outcome, due to the clinical-pathological features of this disease. Optimal treatment remains controversial, especially regarding the extent of surgery, indications for radioiodine and thyroid-stimulating hormone. The correct evaluation of risks before and after surgery facilitates a selective treatment approach; highlighting the importance of reviewing the impact of nuclear medicine on the correct evaluation, treatment and follow-up of patients suffering from this neoplasm.
\end{abstract}

KEY WORDS: Thyroid cancer. Radioiodine. Nuclear medicine.

\section{Introduction}

According to Globocan, in 2012, in Mexico there were 3036 cases of thyroid cancer (725 in men and 2311 in women), which accounted for $2.1 \%$ of total malignant neoplasms. ${ }^{1}$ Differentiated thyroid cancer (DTC) represents at least $85 \%$ of cases and includes the papillary, follicular and Hürtle-cell types. Papillary cancer, the most common type, is associated with an excellent survival, although some patients have a less favorable clinical course, with metastasis or relapses that affect the cervical lymph nodes, and less frequently, lungs and bone.,.$^{2,3}$

Nuclear medicine uses the peculiarities of DTC pathophysiology and plays a highly important role, both in adjuvant treatment and in follow-up and management of relapses. Treatment should be the most efficacious, with the least sequels and lower cost; for this reason, emphasis is made on individualization according to histological type, extension of the disease and risk of relapse.

\section{lodine 131}

lodine 131 ( ${ }^{131}$, radioiodine or RAI) is produced in a nuclear reactor by neutron irradiation of tellurium dioxide during uranium fission. Physical half-life is 8.02 days. Iodine 131 atoms emit $\beta$ particles with several energies, the maximum being $606 \mathrm{keV}$, essential for iodine 131 therapeutic effect; after the $\beta$ particle emission, it emits $\gamma$ rays with energy ranging from 364 to $637 \mathrm{keV}$, which are useful to obtain scintigraphy images or by single photon emission computed tomography (SPECT). lodine 131 is supplied in the form of liquid iodide or in capsules for oral intake. ${ }^{4}$

\section{Radiobiology}

The highest radiation emitted by iodine 131 occurs in the form of $\beta$ particles that interrupt chemicals bonds and inflict devastating damage to the DNA, which causes cell dysfunction and programmed cell death activation. This occurs in two ways: the first one or direct results from $\beta$ particles irradiation on single-strand
Date of reception: 23-01-2017

Date of acceptance: 08-01-2018

DOI://dx.doi.org/10.24875/GMM.M18000182
Gac Med Mex. 2018;154:432-442

Contents available at PubMed www.gacetamedicademexico.com 
DNA, while the second, or indirect, occurs through interaction with water molecules, which forms free radicals that damage the DNA; the latter is the most important due to the larger inflicted damage. ${ }^{5}$

The $\beta$ particles penetrate the tissue a few millimeters. The dose absorbed and delivered by the $\beta$ particles for a given radioactive dose increases with the tissue radius up to $10 \mathrm{~mm}$ and then it remains constant. Since $\beta$ particles virtually do not escape from large tumor deposits, large doses of iodine 131 can be supplied without damaging the surrounding tissues. The lack of homogeneity in the radiation dose is due to iodine 131 irregular distribution in neoplastic foci and to $\beta$ particles' small radius of action.

The $\gamma$ radiation provides only $10 \%$ of total radiation, and only a small fraction of $\gamma$ rays are absorbed by functional tissue, while the largest part leaves through the body surface; this radiation can be detected to be transformed into images and is responsible for the patient to have to remain isolated when doses higher than $30 \mathrm{mCi}$ are administered, according to current international legislation. ${ }^{6}$

lodine 131 efficacy is directly proportional to the uptake and retention by tumor tissue. Effective tumor uptake occurs if it reaches $0.5 \%$ of the iodine 131 dose per gram of tissue and has a biological half-life of four days. With a $150 \mathrm{mCi}$ dose (equivalent to $5.6 \mathrm{GBq}$ ) of iodine 131 , the tumor can receive 25,000 cGy, which equals four times the dose released in an external beam radiation session. ${ }^{7}$

\section{Biology}

lodine is essential for thyroid hormones synthesis. After its intake, it is reduced to iodide in the proximal small intestine. More than $90 \%$ is absorbed during the first 60 minutes. It is distributed in blood as an extracellular ion, similar to chloride, to be incorporated into the cells thanks to the $\mathrm{Na}^{+} / \mathrm{l}^{-}$symporter (NIS). ${ }^{8}$

NIS is a follicular cell basolateral membrane protein. NIS cotransports two sodium ions and one iodide ion. The sodium gradient provides the energy for this transfer and is maintained by the $\mathrm{Na}^{+} / \mathrm{K}^{+}$-ATPase pump. Within the cell, iodine penetrates the apical membrane to the colloid, thanks to transporters such as pendrin. Apical membrane thyroperoxidase (TPO) acts on iodine in three sequential steps: first, it oxidizes it, then it incorporates it to thyroglobulin $(\mathrm{Tg})$ tyrosine residues and, finally, it catalyzes the coupling of two iodinated tyrosine residues to form the future thyroid hormones. This process is called iodine organification. ${ }^{9}$
Then, depending on the need for thyroid hormones by the body, Tg is endocytosed by the apical membrane in the form of colloid drops that are degraded by lysosomal enzymes, releasing triiodothyronine and thyroxine (T3 and T4, respectively) into the bloodstream. This process is regulated by thyroid stimulating hormone (TSH), which after binding to its receptor (TSH-r) in the basolateral membrane, activates cAMP-dependent pathways and induces the transport of iodine by regulating NIS both transcriptional and posttranscriptional expression (Fig. 1).

\section{NIS normal distribution}

In addition to thyroid tissue, mRNA-NIS has been detected in salivary glands, the stomach, thymus and breast, and at low levels in the prostate, ovary, adrenal glands, lung, and heart. ${ }^{10}$ This is consistent with iodine 131 normal uptake in salivary glands, stomach, lactating breast and placenta. Occasionally, iodine $131 \mathrm{ab}-$ sorption is also observed in non-lactating breasts. ${ }^{11}$

\section{NIS expression in thyroid carcinoma}

Using immunohistochemistry with anti-NIS antibodies, NIS is detected at a lower proportion in neoplastic thyroid tissues in comparison with normal tissues, and heterogeneous expression is demonstrated in papillary or follicular carcinoma malignant cells. In neoplastic thyroid tissues, mRNA-NIS expression is 10 to 1200 times lower with regard to normal thyroid tissue; mRNA-TPO expression is reduced 5 to 500 times, while mRNA-Tg expression is 300 -fold lower.12 Notwithstanding, Dohan et $a .^{13}$ reported that $70 \%$ of thyroid tumors show an increase in NIS intracellular expression with regard to healthy thyroid tissue. These discordant results are explained by methodological differences, but it also suggests that although NIS is overexpressed in neoplastic cells, malignant transformation interferes with its correct location within the cell, which impairs its function. ${ }^{14}$

In addition, most researchers document that NIS expression has an inverse relationship with neoplastic cells differentiation. NIS is always expressed in the most differentiated cancers, while it is negative in most poorly differentiated neoplasms. ${ }^{15}$ The location of the transporter on the membrane is indispensable for it to be functional and capture iodine. It is not enough for NIS to be expressed, it has to be located in the cell membrane in order to be entirely functional. ${ }^{16}$ 


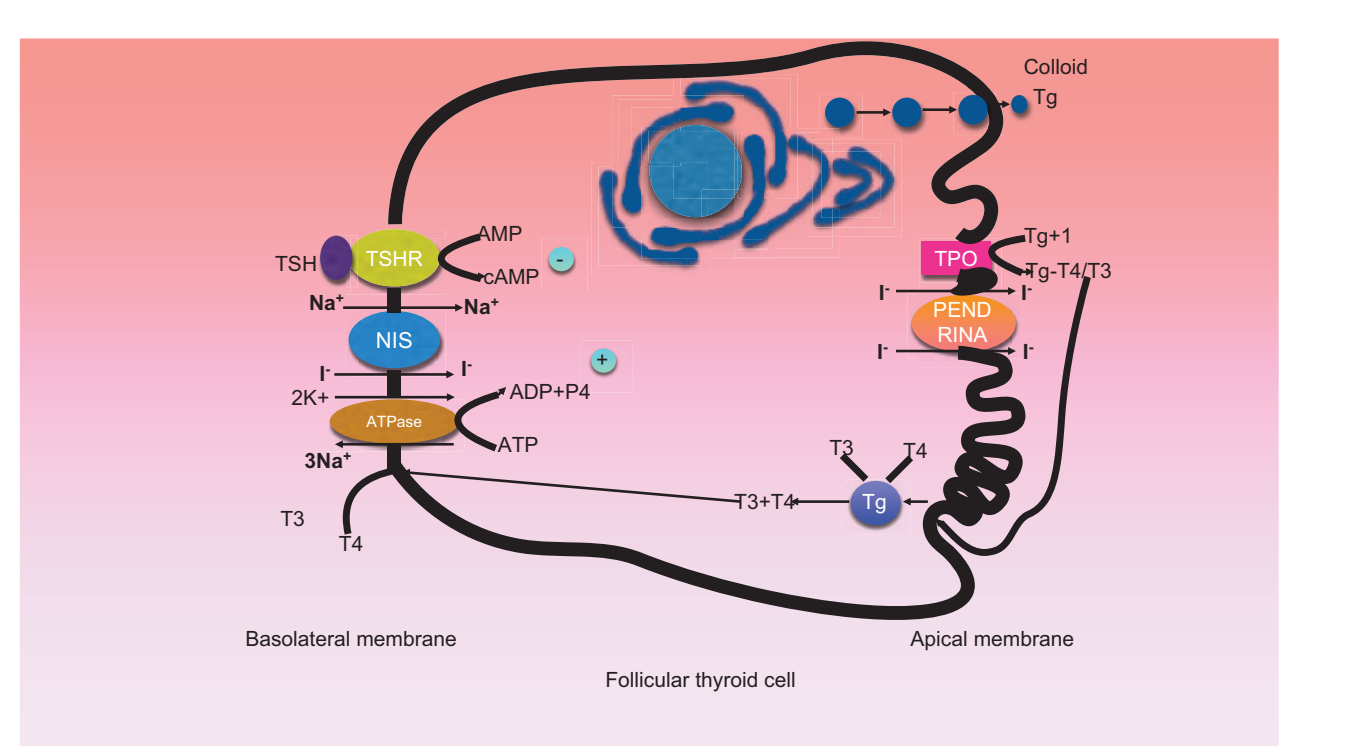

Figure 1. $\mathrm{Na}^{+} / /$symporter (NIS) actively transports iodine together with two sodium atoms into the cell through the basolateral membrane; once inside, iodine crosses the apical membrane towards the colloid thanks to pendrin. The process is regulated by thyroid stimulating hormone.

\section{Ablation and treatment with iodine 131}

lodine 131 uptake of occurs mainly by the influence of TSH and CAMP activation, which increases NIS biosynthesis, but other factors also involved: insulin, insulin-like growth factor 1 (IGF-1) and epidermal growth factor (EGF).

An effective measure is to avoid radioiodinated contrasts for three months and any medication with high iodine content, such as amiodarone, multivitamins, antibiotics (penicillin), cough syrups (ambroxol/dextromethorphan), even some cosmetics contain high amounts of iodine, since they can interfere with iodine 131 action. $^{17}$

\section{Strategies to elevate TSH}

To stimulate iodine 131 uptake by tumor cells, the suppressing medication with levothyroxine is usually eliminated in order to raise endogenous TSH, or recombinant human TSH $\left(\right.$ Thyrogen $^{\circledR}$ ) is administered. This assumes that neoplastic cells preserve certain differentiation and hormonal response. Occasionally thyroid cancer loses this capacity, being associated with a considerably deteriorated prognosis. ${ }^{18}$

After total thyroidectomy, T3, T4 and TSH levels are initially normal and, 2 to 3 weeks later, TSH levels begin to rise, while those of $\mathrm{T} 3$ and $\mathrm{T} 4$ decrease. Usually, hormone replacement therapy is avoided the first 4 to 6 weeks after thyroidectomy if, based on risk assessment, administering iodine 131 has been decided. However, hormone replacement therapy is started immediately in some places. ${ }^{19}$

TSH elevation above $30 \mathrm{mU} / \mathrm{L}$ is necessary to obtain sufficient lodine 131 concentration in NIS-expressing cells. Discontinuing or avoiding hormone replacement therapy for 4 weeks in thyroidectomized individuals reduces T3 and T4 levels and elevates TSH levels. ${ }^{20}$ Consequently, patients are exposed to a prolonged period of hypothyroidism and associated symptoms, with quality of life deterioration, and probability of tumor growth. ${ }^{21}$

Alternatives to avoid the hypothyroid state caused by LT4 discontinuation include the use of recombinant human TSH (rhTSH), which has an identical structure to human TSH, but its glycosylation differs; it has a higher sialic acid content, which is associated with less immune activity, lower affinity for the TSH receptor and lower bioactivity in vitro with regard to human TSH. In patients with DTC and preserved renal function who receive $0.9 \mathrm{mg}$ of rhTSH, it has a half-life of 22 hours. T3 and T4 concentrations increase to 54 and $89 \%$, respectively, between 4 and 8 hours after rhTSH administration, while thyroglobulin peak occurs at 48 hours. ${ }^{22}$ In one study, the radiation exposure rate was compared between individuals undergoing hormone suppression versus rhTSH administration; exposure to radiation was shown to be lower and shorter with the latter, which results in lower thyroglobulin concentration and lower iodine 131 uptake by tumor cells. ${ }^{23,24}$ However, although rhTSH is highly effective, it is relatively expensive. 


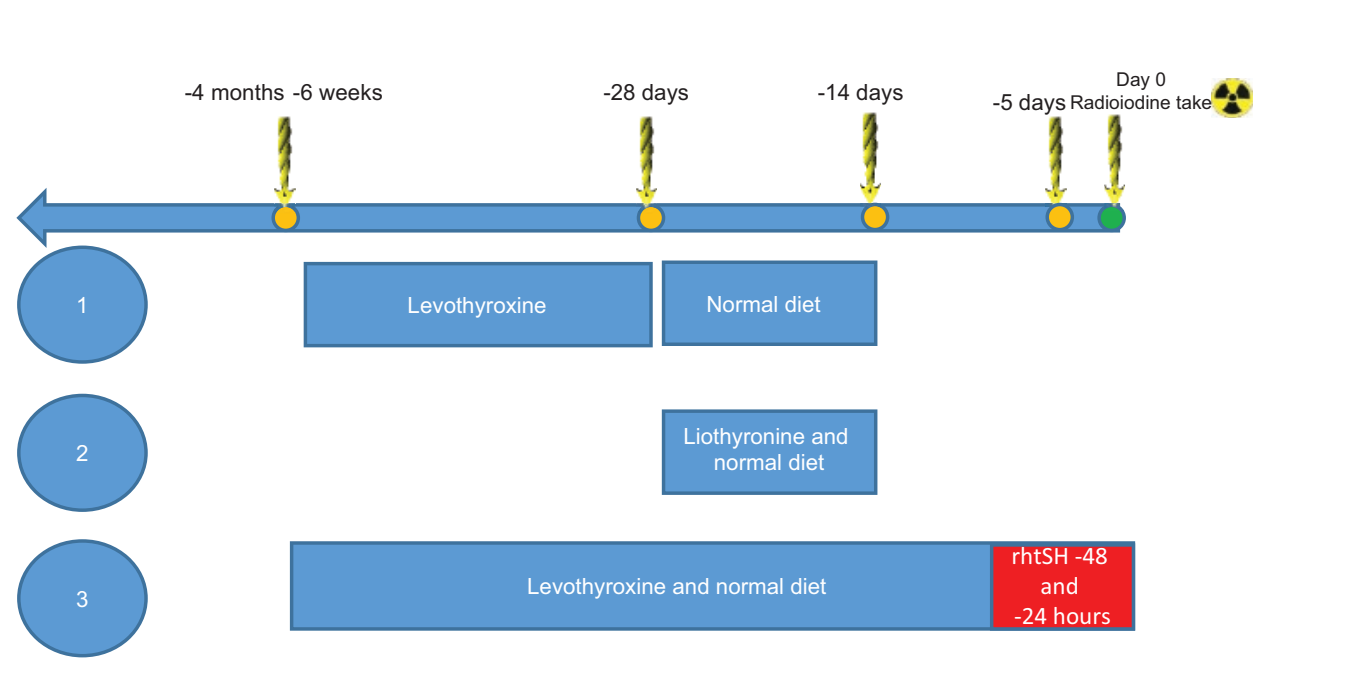

Figure 2. Strategies to increase thyroid-stimulating hormone. To achieve optimal levels for receiving iodine 131, 3 strategies can be followed: discontinuing levothyroxine 4 weeks prior to iodine 131 administration, exchanging levothyroxine for liothyronine, which is to be discontinued 2 weeks prior to iodine 131, and choosing to administer TSH without thyroid hormones being discontinued.

A third strategy is to replace LT4 with LT3; the latter has much shorter half-life: 1 to 3 days (instead of 7 days of LT4), and for this reason it can be discontinued for less time to elevate TSH levels. ${ }^{25}$ Patients who discontinue LT4 and replace it with LT3, undergo only 2 weeks of hypothyroidism, while with LT4 it is 4 .

The need to follow a low iodine diet two weeks prior to iodine 131 administration to obtain a $<50 \mu \mathrm{g} / \mathrm{gCr}$ ioduria has been pointed out; ${ }^{26}$ previously, uptake by tumor cells had been shown to increase to the double after a low-iodine diet. Nevertheless, there are no studies examining whether a low iodine diet impacts on the rate of relapse or mortality. ${ }^{27}$

rhTSH is reserved for patients in whom a hypothyroid status can worsen an underlying medical condition, such as poorly controlled metabolic syndrome, chronic kidney disease (GFR $<50 \mathrm{mg} / \mathrm{mL}$ ), major depression, cardiac arrhythmia (particularly if the patient is on treatment with amiodarone and it is irreplaceable) or in patients with voluminous residual or metastatic tissue that prevents TSH elevation owing to continuous production of thyroid hormones. ${ }^{28}$

The BTA guidelines suggests that, in patients with T1-T3, N0, N1a, M0 and R0, the method of choice is to administer rhTSH; but in high-risk patients, on relapse or with metastatic disease, the method of choice should be to discontinue LT4; however, prospective studies are required to support such recommendation.

Regardless of the strategy, TSH levels should be corroborated to be optimal when receiving iodine 131, i.e., above $30 \mathrm{mU} / \mathrm{L}$; usually, TSH is measured together with thyroglobulin $(\mathrm{Tg})$ and anti-thyroglobulin antibodies (anti-Tg-Ab) (Fig. 2). ${ }^{29}$

\section{Risk assessment}

Controversies still exist regarding ablation with RAI, but it is claimed that iodine 131 administration simplifies follow-up by eliminating Tg-producing normal or neoplastic thyroid tissue, which facilitates relapse identification by measuring $\mathrm{Tg}$ and avoiding anti-Tg antibodies (anti-Tg-Ab) continuous production. ${ }^{30}$ The decision to administer ablative doses should be rational, based on risk assessment. The American Thyroid Association (ATA 2015) and the British Thyroid Association (BTA, 2014) guidelines propose similar systems, even the National Comprehensive Cancer Network (NCCN V1.2016) agrees on several points (Table 1). ${ }^{31,32}$

The ATA guidelines arose from the inability of other systems to establish the risk for relapse; previous systems are only useful to establish mortality risk. It is a fact that a patient with low mortality risk can be at high risk of relapse; for this reason, ATA, BTA and NCCN recommend assessing the risk for relapse in all patients.

\section{Who should receive iodine 131 and which is the appropriate dose?}

The purpose of administering iodine 131 is to eliminate any thyroid carcinoma and normal thyroid tissue microscopic deposit. NCCN and ATA propose 3 goals:

- Remnant thyroid tissue ablation (the term ablation should only be used when the first iodine 131 dose is administered in order to simplify follow-up).

- Adjuvant therapy, to eliminate subclinical micrometastases. 
Table 1. Thyroid cancer risk groups according to the American Thyroid Association

\begin{tabular}{|c|c|c|c|}
\hline Low risk & ntermediate risk & High risk & \\
\hline $\begin{array}{l}\text { All the following are present: } \\
\text { - No metastasis. } \\
\text { - Complete resection. } \\
\text { - No extrathyroidal extension. } \\
\text { - No aggressive histology. } \\
\text { - No vascular invasion. } \\
\text { - No uptake outside the thyroid bed post-ablation } \\
\text { with iodine } 131 \text {. } \\
\text { - NO, < } 5 \text { N1 micrometastases. } \\
\text { - Intrathyroidal, encapsulated follicular variant. } \\
\text { - Intrathyroidal, well differentiated follicular } \\
\text { carcinoma with minimal capsular invasion and no } \\
\text { or minimal vascular invasion (< } 4 \text { foci). } \\
\text { - Uni- or multifocal intrathyroidal papillary } \\
\text { microcarcinoma without BRAF V600E mutation. }\end{array}$ & $\begin{array}{l}\text { Any of the following is present: } \\
\text { - Microscopic extrathyroidal extension. } \\
\text { - lodine } 131 \text { uptake outside the thyroid bed } \\
\text { after remnants ablation. } \\
\text { - Aggressive histology (tall cells, insular, } \\
\text { columnar, hobnail variants, Hurthle cells). } \\
\text { - Papillary carcinoma with vascular invasion. } \\
\text { - Pathologic N1 ( } 5 \text { pathologic lymph nodes) } \\
\text { with global dimension no larger than } 3 \mathrm{~cm} \text {. } \\
\text { - Multifocal papillary carcinoma with minimal } \\
\text { extrathyroidal extension and BRAF V600E } \\
\text { mutation. }\end{array}$ & \multicolumn{2}{|c|}{$\begin{array}{l}\text { Any of the following is present: } \\
\text { - Macroscopic extrathyroidal } \\
\text { extension. } \\
\text { - Incomplete tumor resection (R2). } \\
\text { - Metastases. } \\
\text { - Post-surgery Tg elevated levels. } \\
\text { - Pathologic N1 with any number of } \\
\text { metastatic lymph nodes or global } \\
\text { dimension larger than } 3 \mathrm{~cm} \text {. } \\
\text { - Follicular carcinoma } \\
\text { with extensive vascular } \\
\text { invasion (> } 4 \text { foci). } \\
\begin{array}{ll} \\
\end{array}\end{array}$} \\
\hline
\end{tabular}

- Therapeutic dose to treat local persistence or confirmed metastases.

However, for practical purposes, iodine 131 administration is usually classified as ablation and treatment. lodine 131 efficiency is inversely proportional to the volume of residual thyroid tissue and directly proportional to TSH levels, and all macroscopic disease must therefore be surgically removed. ${ }^{33}$

To date, there are three approaches to define the iodine 131dose: fixed dose, dose determined by blood upper limit and quantitative tumor dosimetry, with the latter two being often reserved for patients with metastases or for unusual situations, such as kidney failure, children, older patients, and those with extensive pulmonary metastases; due to its complexity, the fixed doses strategy is favored. ${ }^{34}$

\section{Patients with low risk}

Prospective studies of the National Thyroid Cancer Treatment Cooperative Study Group (NTCTCSG) suggest that progression-free survival and overall disease-specific survival do not improve with iodine 131 treatment in stage I or II patients. A retrospective multicenter study, where 1298 low-risk patients were assessed with a mean follow-up of 10.3 years, failed to find benefits from iodine 131 ablation in terms of overall survival and progression-free survival. ${ }^{35}$ Specifically, there is scant evidence that supports the use of iodine 131 in these patients.

Although there are no advantages in terms of survival, certain studies have shown the convenience of low versus high doses in patients with low risk, regardless of the stimulation method. ${ }^{36}$ Cheng et al. ${ }^{37}$ analyzed 9 randomized studies that included 2569 low-risk patients and different TSH stimulation methods (rhTSH and hormone withdrawal). They found no differences in iodine 131 efficacy between $30 \mathrm{mCi}$ and $100 \mathrm{mCi}$.

Ablation with 30 versus $100 \mathrm{mCi}$ is equivalent, regardless of the stimulation method; the advantage of doses not exceeding $30 \mathrm{mCi}$ lies in that patients do not require hospitalization, there is similar quality of life and iodine 131-related side effects, such as sialadenitis, edema, nausea and vomiting are lower; in addition, there is a lower radiation exposure rate and lower cumulative dose. Recent analyses and systematic reviews support these conclusions. ${ }^{38}$

\section{Patients with intermediate risk}

Regarding this category, there are discrepancies in the literature ${ }^{39}$ lodine 131 administration in patients with histologically aggressive tumors (tall cells, diffuse sclerosing, etc.), overall survival is improved; however, in studies with patients with positive lymph nodes, microscopic extrathyroidal extension or tumor $>4 \mathrm{~cm}$, survival is similar if patients are younger than 45 years, although follow-up time did not exceed 7 years. On the other hand, there is an advantage in $>45$-year individuals who received treatment; although it did not exceed $73 \%$, it was higher than $69 \%$ of the group that did not received it. ${ }^{40}$ Lamartina et al., ${ }^{41}$ in the review of 13 nonrandomized studies, did not find any benefits, whereas 11 supported its use. We consider that firther studies are required, with standardized and homogeneous criteria.

\section{Patients with high risk}

Routine ablation is recommended in patients with high risk, and it is suggested that the first dose of iodine 
131 should not exceed $150 \mathrm{mCi}$, especially in > 45-year individuals. ${ }^{42}$ Different approaches have been proposed for the treatment of relapse or persistence. The concept of high fixed doses was used, i.e. 100-150 mCi, if persistence or relapse was confined to the thyroid bed; $150-175 \mathrm{mCi}$ if there was lymph node involvement, 200-250 $\mathrm{mCi}$ if there was metastasis to the lung; in case of bone metastases, $200-300 \mathrm{mCi}$ were resorted to. ${ }^{43}$ However, iodine 131 effectiveness is related to the dose of radiation released into neoplastic tissue and its radiosensitivity. Thus, radiosensitivity is higher in young people $(<45$ years), with small metastases $(<10 \mathrm{~mm})$, well-differentiated (papillary and follicular) and iodine 131-avid tumors.

Currently, it is recognized that the maximum tolerated radiation dose (MTRD) absorbed in blood is $200 \mathrm{cGy},{ }^{44}$ and at older age renal function decreases, as it occurs in patients with kidney failure or heart failure, and thereby iodine 131 clearance decreases. ${ }^{45}$ In this regard, Tuttle et al. ${ }^{46}$ demonstrated that empirical doses of $140 \mathrm{mCi}$ exceeded the MTRD by less than $7 \%$ in patients $<70$ years; this percentage increased to $13 \%$ in patients > 80 years; on the other hand, the 200 and $250 \mathrm{mCi}$ doses exceeded the MTRD in 15 and $22 \%$ of subjects $<70$ years, respectively, while in patients $>70$ years, in up to 38 and 50 $\%$, respectively. Administering doses $>200 \mathrm{mCi}$ is possible as long as a previous dosimetric study is performed and patients are $<65$ years of age.

Currently, administering iodine 131 at doses $>200 \mathrm{mCi}$ is not recommended, since its superiority has not been demonstrated and, conversely, radiation exposure is higher, side effects are more common and prolonged and cumulative dose is higher without better survival.

\section{Usefulness of pre- and post-iodine 131 treatment scanning}

Some nuclear medicine centers perform a full body scan before an ablative or therapeutic dose in order to estimate the iodine 131 required dose. With the availability of SPECT/CT equipment, sensitivity and specificity with regard to planar imaging has increased. Planar imaging reaches a sensitivity of $41 \%$ and specificity of $68 \%$, whereas SPECT sensitivity is $45 \%$ and specificity $89 \%$. With SPECT/CT, sensitivity is increased to up to $50 \%$ and specificity reaches $100 \% .{ }^{47}$

Avram et al., in a series of 320 patients who underwent SPECT/CT pre-iodine 131 ablation, re-staged $4 \%$ of patients $<45$ years of age and $25 \%$ of those
$>45$ years old. ${ }^{48}$ With the widespread use of clinico-pathological factors, pre-ablation imaging is currently not recommended as a strategy to define the dose, however, it may be necessary in patients in whom residual disease has not been evaluated with histopathological study or ultrasound.

"Stunning" is defined as a decrease in iodine 131 uptake by neoplastic thyroid cells after administration of a iodine 131diagnostic dose. ${ }^{49}$ It may be due to a reduction in the number of functional thyroid cells owing to cell death produced by iodine $131 \beta$ radiation or by a decrease in the capability of viable thyroid cells to trap or retain lodine 131 during a time interval. Guiraud-Vitaux et al. ${ }^{50}$ point out that there may be infra-therapeutic necrosis due to high doses of iodine 131 , which would imply a reduction in the efficacy of therapeutic doses after diagnostic imaging. However, investigation of this phenomenon has led to contradictory conclusions. ${ }^{51}$ Recent investigations have demonstrated that it is a radiobiological phenomenon that is closely related to the absorbed radiation, rather than to the administered dose, and that stunning is often observed 48 hours after a iodine 131 dose. ${ }^{52}$

In a different train of thought, practicing a body scan 5 to 8 days after ablation or therapeutic dose is recommended, as it identifies additional metastatic foci in 10 to $26 \%$ of patients when compared to a diagnostic scan.

SPECT/CT improves sensitivity to up to $78 \%$ and specificity to up to $100 \%$, thus reducing the need for sectional studies in $20 \%$ (Fig. 3)..$^{53}$

\section{Follow-up}

Full-body scanning plus SPECT/CT with iodine 131 is used for follow-up, at least 6 months after the dose for ablation or therapy according to ATA, or 9 according to BTA, under three scenarios: patients with abnormal uptake outside the thyroid bed after post-treatment or post-ablation scanning; in patients with scant information on post-ablation scan due to large remnants that hinder defining if there was uptake outside the thyroid bed; and in patients with presence or de novo appearance of anti-Tg-Abs, even in the absence of suspicious findings of residual disease by ultrasound.

Clinical, biochemical and imaging findings during follow-up must be put together in order to redefine the treatment, provide the most appropriate therapy and define the response. Tuttle et al. ${ }^{54}$ and Vaisman et al. ${ }^{55}$ have contributed to a better evaluation by defining four response categories: 


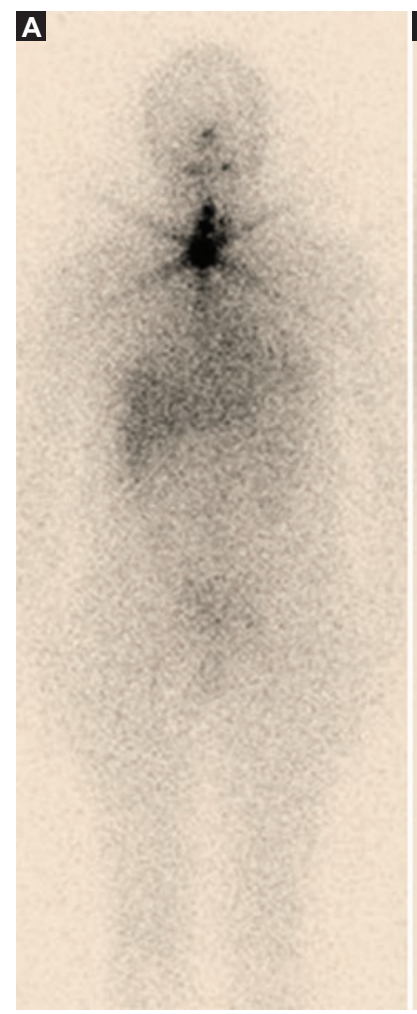

\section{B}
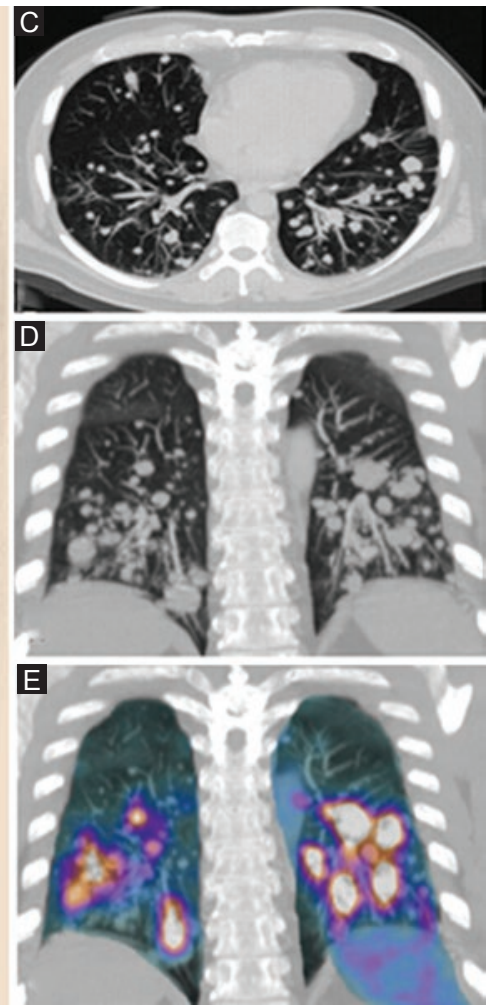

Figure 3. (A) Anterior projection planar scan performed 48 hours after administering $5 \mathrm{mCi}$ of iodine 131. Intense abnormal focal uptake limited to the thyroid bed is observed. Owing to respiratory symptomatology, a non-contrasted computed tomography was performed, where multiple nodular images consistent with pulmonary metastases were observed in both lungs (C and D); therefore, administering $200 \mathrm{mCi}$ of iodine 131 was decided; seven days later, on anterior projection planar scan, intense uptake was observed in the thyroid bed in both lungs (B). After the scan, SPECT/CT revealed pulmonary infiltrate and iodine 131uptake, not visualized in pre-ablation planar scan (E).

- Excellent response, which is obtained when there is no evidence of structural disease by imaging (with ultrasound or SPECT/CT imaging), as well as clinically or by biochemistry ( $\mathrm{Tg}$ suppressed < $0.2 \mathrm{ng} / \mathrm{mL}$ or stimulated $<1 \mathrm{ng} / \mathrm{mL}$ ). It occurs in 86 to $91 \%$ of patients with low risk, in 57 to 63 $\%$ of patients with intermediate risk and in 14 to $16 \%$ of those with high risk.

- Incomplete biochemical response, which occurs when there is a negative imaging method, but suppressed $\mathrm{Tg}$ levels $>1 \mathrm{ng} / \mathrm{mL}$, stimulated $\mathrm{Tg}>10 \mathrm{ng} / \mathrm{mL}$ or anti-Tg-Ab elevation. This response is presented by 11 to $19 \%$ of low-risk patients, 21 to $22 \%$ of those with intermediate risk and 16 to $18 \%$ of those with high risk.

- Incomplete structural response, which refers to patients with structural or functional disease by any imaging method, with any levels of $\mathrm{Tg}$ or anti$\mathrm{Tg}-\mathrm{Ab}$, and it occurs in 2 to $6 \%$ of patients with low risk, 19 to $28 \%$ with intermediate risk and 67 to $75 \%$ with high risk.

- Indeterminate response, which refers to nonspecific findings in imaging studies, suppressed Tg levels
$<1 \mathrm{ng} / \mathrm{mL}$, stimulated Tg levels $<10 \mathrm{ng} / \mathrm{mL}$ or anti$\mathrm{Tg}$-Ab stable levels. This response is present in 12 to $29 \%$ of patients with low risk, 8 to $23 \%$ with intermediate risk and 0 to $4 \%$ with high risk.

Performing full scans with SPECT/CT is not enough, they must be correlated with specific markers, Ig and anti-Tg antibodies. It is well known that Tg levels measurements are of particular importance for the monitoring of patients with residual disease and relapse. In the absence of anti-Tg-Abs, Tg has elevated sensitivity and specificity to document relapse or persistence of the disease. Numerous authors recommend its measurement with stimulated TSH, since it can increase $T g$ levels between 5 and 10 times. Stimulated Tg levels $<1 \mathrm{ng} /$ $\mathrm{mL}$ or absence of anti-Tg antibodies have $98 \%$ probability to identify patients with absence of disease..$^{56}$

On the other hand, anti-Tg-Abs may be present or appear de novo in up to $25 \%$ of patients, particularly in those with Hashimoto's thyroiditis. ${ }^{57}$ Thyroid autoimmune diseases are associated with the production of antibodies in intrathyroideal lymphocytes and, after total thyroidectomy, levels remain elevated for years without evidence of disease. The reason is that 

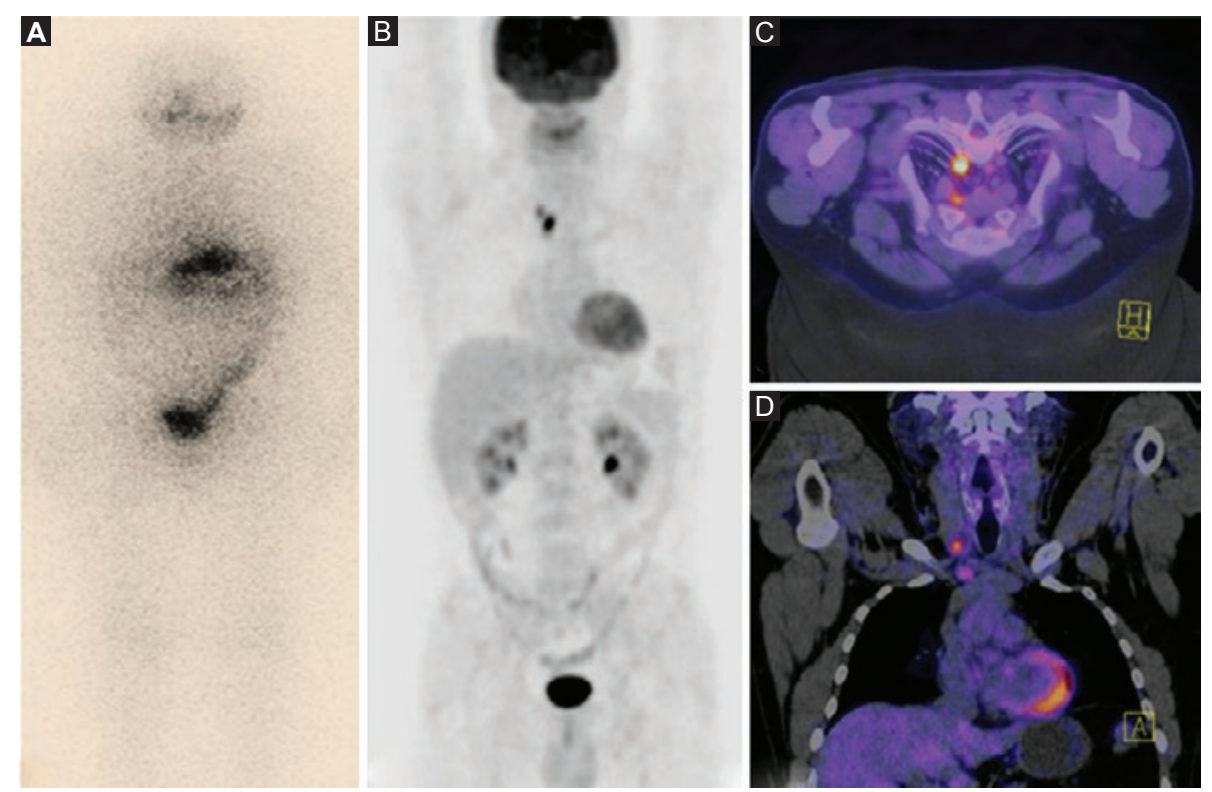

Figure 4. (A) Anterior projection planar scan performed 48 hours after the administration of $5 \mathrm{mCi}$ of iodine 131. Usual biodistribution and elimination pathways were observed, without abnormal uptake focal areas in a patient with stimulated TSH and $\mathrm{Tg}>100 \mathrm{ng} / \mathrm{m} \mathrm{L}$. (B) Seven days later, a PET/CT-FDG was practiced, where abnormal focal uptake was observed on the right parasternal midline. (C and D) On axial and coronal slices, two nodules with radiotracer intense uptake at level VI right cervical lymph nodes and level $1 R$ and $3 \mathrm{~A}$ mediastinal lymph nodes were appreciated.

autoimmune response starts and spreads in the cervical lymph nodes in response to $\mathrm{Tg}$ in antigen-presenting cells. Anti-Tg-Abs half-life after total thyroidectomy is 10 weeks, with rapid decrease due to the formation of Tg-anti-Tg antibody complexes in response to $\mathrm{Tg}$ elevation after surgery..$^{58}$

Surgery can trigger or promote anti-Tg-Abs de novo appearance, which tend to decline in the course of months. Patients may not reach an anti-Tg-Ab negative status during the first postoperative year and even exhibit an increase (or de novo appearance) within the 6 months following iodine 131 treatment when there is $\mathrm{Tg}$ release secondary to thyroid tissue radiolytic damage. ${ }^{59}$

For an efficacious anti-Tg-Ab long-term follow-up, it is essential for a sensitive method to be used every 6 to 12 months. Kim et al. ${ }^{60}$ found that in patients with a decrease higher than $50 \%$ in anti-Tg-Ab between 6 and 12 months after iodine $131,<1 \%$ developed relapse. In contrast, $19 \%$ of patients with less than 50 $\%$ decrease in the same interval experienced relapse, while $37 \%$ of those in whom levels were increased showed relapse.

\section{The role of PET/CT with 2-deoxy-2-[18F]- fluoro-D-glucose (PET/CT-FDG)}

PET/CT-FDG is a valuable tool in patients with $\mathrm{Tg}$ levels elevation or anti-Tg antibodies and negative iodine 131 scan.$^{61}$ In thyroid neoplasms, radiopharmaceutical 18F-FDG uptake is limited to more aggressive or high-grade tumors, with no or poor uptake by well-differentiated tumors, a phenomenon that Feine et al. ${ }^{62}$ named "flip-flop".

Owing to its hydrophilic nature, glucose requires GLUT (glucose-transporting transmembrane proteins) to enable for it to cross the cell membrane. GLUT1 overexpression in the cell membrane of thyroid neoplasms is closely related to tumors with more aggressive biological behavior. In addition, TSH plays an important role, since it stimulates glucose transport and glycolytic activity in thyrocytes by means of GLUT1 translocation, as well as GLUT1 neosynthesis by activation of its gene expression, which indicates that PET/CT-FDG is influenced by TSH levels. ${ }^{63}$

Salvatori et al. ${ }^{64}$ suggest that the indications to practice PET/CT-FDG should be divided into strongly defined and not completely defined. In the former, patients with high levels of $\mathrm{Tg}(>10 \mathrm{ng} / \mathrm{mL})$ and negative imaging study (ultrasound, iodine 131 scan) should be included. Anti-Tg-Ab elevation or de novo appearance can drastically alter $\mathrm{Tg}$ values; therefore, anti-Tg-Ab elevation or de novo appearance in the presence of $\mathrm{Tg}$ levels $<2 \mathrm{ng} / \mathrm{mL}$ is also an indication.

The prognostic importance of PET/CT-FDG lies in that most patients with metastatic disease show avidness for 18F-FDG, which suggests higher aggressiveness, dedifferentiation and metabolically active cells; 

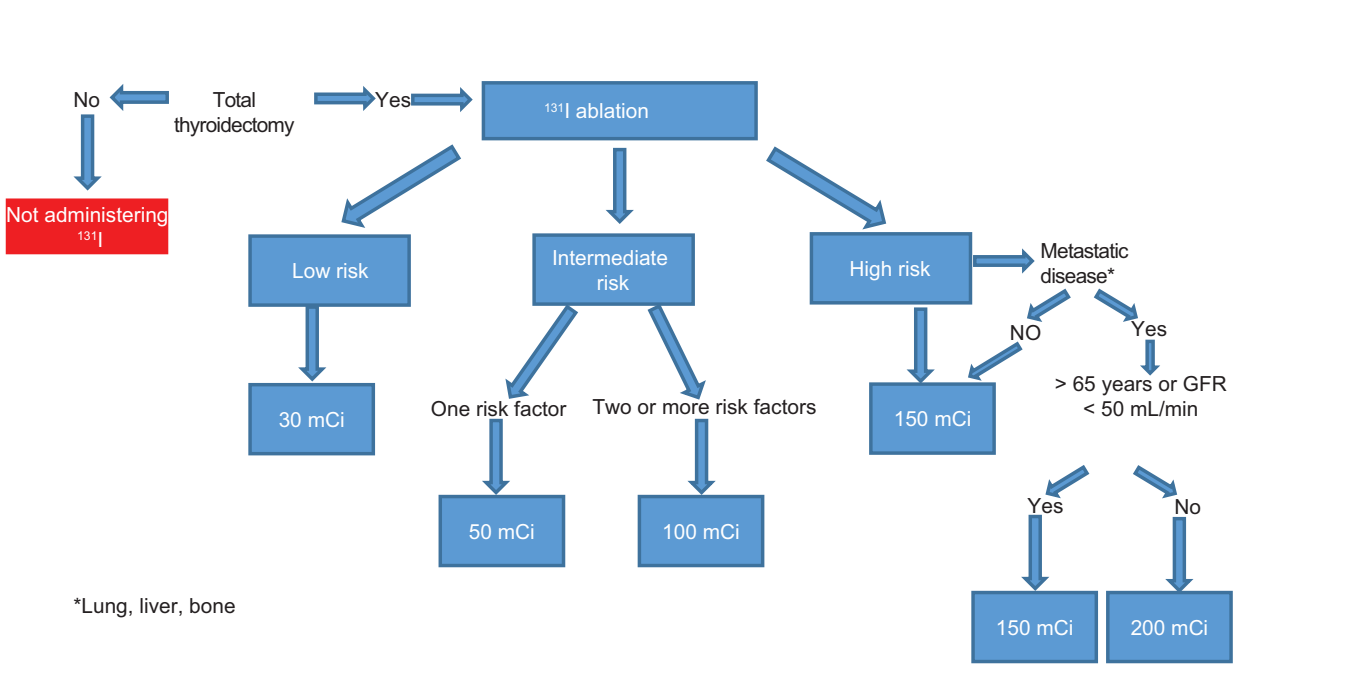

Figure 5. Recommendations according to post-radioiodine administration clinical scenario, based on the reviewed literature and with no unification of established criteria for intermediate and high risk groups.

a negative PET/CT-FDG predicts a favorable prognosis. ${ }^{65}$ In a multivariate analysis, Wang et al. ${ }^{66}$ analyzed 400 patients with high-risk characteristics; they observed that age and a PET/CT-FDG are the most important prognostic factors, since there is an inverse relationship between survival and the number of metabolically active lesions.

Sensitivity and specificity are related to Tg levels. In a meta-analysis, Leboulleux ${ }^{67}$ demonstrated that sensitivity and specificity are strongly influenced by a $\mathrm{Tg}$ cut-off point of $>10 \mathrm{ng} / \mathrm{mL}$, with the values being 83 and $84 \%$, respectively, in patients with disease with no iodine uptake. Another analysis showed that sensitivity at Tg levels $<10 \mathrm{ng} / \mathrm{mL},>10$ but $<100 \mathrm{ng} / \mathrm{mL}$ and $>100 \mathrm{ng} / \mathrm{mL}$ was $10.5,75.6$ and $91 \%$, respectively. In addition, sensitivity also depends on the site and size of metastases. For lymph node metastases $<10 \mathrm{~mm}$, sensitivity is $69.7 \%$ and specificity $83.3 \%$, whereas for $>11 \mathrm{~mm}$, sensitivity was $95.7 \%$ and specificity $80 \%$. On the other hand, with pulmonary metastases $<10 \mathrm{~mm}$, sensitivity was $41 \%$ and specificity $80 \%$; for > $11 \mathrm{~mm}$, sensitivity was $94 \%$ and specificity $89 \% .{ }^{68}$

As previously mentioned, SPECT/CT sensitivity is higher, so that the absence of findings with $\mathrm{Tg}$ elevated levels or anti-Tg-Ab also indicates the need for PET/CT-FDG (Fig. 4).

Owing to the recent implementation in some centers with regard to oncogenic mutations related to BRAF (V600E), there are some studies that demonstrate the existence of a correlation with hypermetabolism in patients with this mutation..$^{69}$ Nagarajah et al. ${ }^{70}$ showed that in a sample of 48 patients with DTC, 24 had BRAF mutation (V600E) and 24, wild-type BRAF; they observed a significantly higher correlation of metabolic activity in patients with BRAF mutation (V600E), and concluded that a high metabolic rate may be related to gene mutation, which entails higher tumor aggressiveness and worse prognosis; however, further studies are required to correlate these findings.

Indications that are not completely defined include the practice of PET CT in patients with refractory disease, to assess the response to treatment with targeted therapies, in staging and monitoring of highrisk histologies, in indeterminate thyroid nodules after aspiration biopsy and, recently, for radio-guided surgery. ${ }^{71}$

Figure 5 illustrates the follow-up and treatment of patients with DTC managed with iodine 131.

\section{Acknowledgements}

To doctors Claudia Mosqueda and Angélica Arellano, for their collaboration in the generation and editing of illustrations.

\section{References}

1. Ferlay J, Soerjomataram I, Ervik M, Dikshit R, Eser S, Mathers C, et al. GLOBOCAN 2012 v1.0, Cancer incidence and mortality worldwide: IARC Cancer Base No. 11. Lyon, France: International Agency for Research on Cancer 2013. Disponible en: http://globocan.iarc.fr, accessed on 20/December/2016

2. Bongiovanni M, Paone G, Ceriani L, Pusztaszeri M. Cellular and molecular basis for thyroid cancer imaging in nuclear medicine. Clin Trans Imaging. 2013;1:149-161.

3. Granados-García M, León-Takahashi AM, Guerrero-Huerta FJ, Taissoun-Aslan ZA. Cáncer diferenciado de tiroides: una antigua enfermedad con nuevos conocimientos. Gac Med Mex. 2014;150:65-77.

4. Robbins $R$, Schulemberg $M$. The evolving role of 131 l for the treatment of differentiated thyroid carcinoma. J Nucl Med. 2005;46:28S-37S.

5. Maxon HR, Thomas SR, Hertzberg VS, Kereiakes JG, Chen IW, Sperling MI, et al. Relation between effective radiation dose and outcome of radioiodine therapy for thyroid cancer. N Engl J Med. 1983;309: 937-941.

6. Braunstein GD (editor). Thyroid Cancer. Volume 32 of Endocrine Updates. EE.UU.: Springer Science \& Business Media; 2011. 
7. Dorn R, Kopp J, Vogt H, Heidenreich P, Carroll RG, Gulec SA. Dosimetry-guided radiactive iodine treatment in patients with metastatic differentiated thyroid cancer. Largest safe dose using a risk-adapted approach. J Nucl Med. 2003:44:451-456.

8. Eskandari S, Loo DD, Dai G, Levy O, Wright EM, Carrasco N. Thyroid $\mathrm{Na}+/ /$-symporter. Mechanism, stoichiometry, and specificity. J Biol Chem. 1997;272:27230-27238

9. De-La-Vieja A, Dohan O, Levy O, Carrasco N. Molecular analysis of the sodium/iodide symporter: impact on thyroid and extrathyroid pathophysiology. Physiol Rev. 2000;80:1083-1105.

10. Caillou B, Troalen F, Baudin E, Talbot M, Filetti S, Schlumberger M, et al. $\mathrm{Na}+/ /$ - symporter distribution in human thyroid tissues: an immunohistochemical study. J Clin Endocrinol Metab. 1998;83:4102-4106.

11. Daniels GH, Haber DA. Will radioiodine be useful in treatment of breast cancer? Nat Med. 2000;6:859-860.

12. Filetti S, Bidart JM, Arturi F, Caillou B, Russo D, Schlumberger M. Sodium/iodide symporter: a key transport system in thyroid cancer cell metabolism. Eur J Endocrinol. 1999;141:443-457.

13. Dohán O, Baloch Z, Banrevi Z, Livolsi V, Carrasco N. Predominant intracellular overexpression of the $\mathrm{Na}+/ \mathrm{l}+$ symporter (NIS) in a large sampling of thyroid cancer cases. J Clin Endocrinol Metab. 2001;86: 2697-2700.

14. Saito T, Endo T, Kawaguchi A, Ikeda M, Katoh R, Kawaoi A, et al. Increased expression of the sodium/iodide symporter in papillary thyroid carcinomas. J Clin Invest. 1998;101:1296-1300.

15. Min JJ, Chung JK, Lee YJ, Jeong JM, Lee DS, Jang JJ, et al. Relationship between differentiation and expression of sodium/iodide symporter or glucose transporter-1 in differentiated thyroid carcinoma. J Nucl Med. 2001:42:133P.

16. Wapnir IL, Van-De-Rijn M, Nowels K, Amenta PS, Walton K, Montgomery $\mathrm{K}$, et al. Immunohistochemical profile of the sodium/iodide symporter in thyroid, breast, and other carcinomas using high-density tissue microarrays and conventional sections. J Clin Endocrinol Metab. 2003;88:1880-1888

17. Sawka AM, Ibrahim-Zada I, Galacgac P, Tsang RW, Brierley JD, Ezzat S, et al. Dietary iodine restriction in preparation for radiactive iodine treatment or scanning in well-differentiated thyroid cancer: a systematic review. Thyroid. 2010;20:1129-1138.

18. Thyroid cancer. En: Clinical Practice Guidelines in Oncology. EE.UU.: National Comprehensive Cancer Network

19. Haugen BR, Alexander EK, Bible KC, Doherty GM, Mandel SJ, Nikiforov YE, et al. 2015 American Thyroid Association Management Guidelines for Adult Patients with Thyroid Nodules and Differentiated Thyroid Cancer: The American Thyroid Association Guidelines Task Force on Thyroid Nodules and Differentiated Thyroid Cancer. Thyroid. 2016;26:1-133.

20. Golger A, Fridman TR, Eski S, Witterick IJ, Freeman JL, Walfish PG. Three-week thyroxine withdrawal thyroglobulin stimulation screening test to detect low-risk residual/recurrent well-differentiated thyroid carcinoma J Endocrinol Invest. 2003;26:1023-1031.

21. Dow KH, Ferrell BR, Anello C. Quality-of-life changes in patients with thyroid cancer after withdrawal of thyroid hormone therapy. Thyroid. 1997:7:613-619

22. Almeda-Valdés $P$, Arechavaleta-Granell $M$, Bolaños-Gil-De-Montes $F$, Cuevas-Ramos D, Gamboa-Domínguez A, Gómez-Cruz R, et al. Guía clínica para el diagnóstico y tratamiento del cáncer diferenciado de tiroides. México: Sociedad Mexicana de Nutrición y Endocrinología; 2009.

23. Pötzi C, Moameni A, Karanikas G, Preitfellner J, Becherer A, Pirich C et al. Comparison of iodine uptake in tumour and nontumour tissue under thyroid hormone deprivation and with recombinant human thyrotropin in thyroid cancer patients. Clin Endocrinol (Oxf). 2006;65:519-523.

24. Rosário PW, Borges MA, Purisch S. Preparation with recombinant human thyroid-stimulating hormone for thyroid remnant ablation with 1311 is associated with lowered radiotoxicity. J Nucl Med. 2008;49:1776-1782.

25. Leboeuf R, Perron P, Carpentier AC, Verreault J, Langlois MF. L-T3 preparation for whole-body scintigraphy: a randomized-controlled trial. Clin Endocrinol (Oxf). 2007:67:839-844.

26. Pluijmen MJ, Eustatia-Rutten C, Goslings BM, Stokkel MP, Arias AM Diamant $M$, et al. Effects of low-iodide diet on postsurgical radioiodide ablation therapy in patients with differentiated thyroid carcinoma. Clin Endocrinol (Oxf). 2003;58:428-435.

27. Sonenberg M. Low-iodine diet in the treatment of differentiated thyroid cancer with radiactive iodine. Endocrine. 2002;17:141-143.

28. Robbins RJ, Driedger A, Magner J. Recombinant human thyrotropin-assisted radioiodine therapy for patients with metastatic thyroid cancer who could not elevate endogenous thyrotropin or be withdrawn from thyroxine. Thyroid. 2006;16:1121-1130.

29. Liel $Y$. Preparation for radiactive iodine administration in differentiated thyroid cancer patients. Clin Endocrinol (Oxf). 2002;57:523-527.

30. Van-Nostrand D, Wartofsky L. Radioiodine in the treatment of thyroid cancer. Endocrinol Metab Clin North Am. 2007;36:807-822.

31. Perris P, Colley S, Boelaert K, Evans C, Evans RM, Gerrard GE, et al. British Thyroid Association Guidelines for the Management of Thyroid Cancer. Clin Endocrinol. 2014;81:1-122.
32. Carty SE, Doherty GM, Inabnet WB, Pasieka JL, Randolph GW, Shaha AR, et al. American Thyroid Association statement on the essential elements of interdisciplinary communication of perioperative information for patients undergoing thyroid cancer surgery. Thyroid. 2012; 22:395-399

33. Verkooijen RB, Verburg FA, Van-Isselt JW, Lips CJ, Smit JW, Stokkel MP. The success rate of I-131 ablation in differentiated thyroid cancer: comparison of uptake-related and fixed-dose strategies. Eur $\mathrm{J}$ Endocrinol. 2008:159:301-307.

34. Robbins RJ, Schlumberger MJ. The evolving role of 131 l for the treatment of differentiated thyroid carcinoma. J Nucl Med. 2005;46:28S-37S

35. Schvartz C, Bonnetain F, Debakuyo S, Gauthier M, Cueff A Fieffé S, et al. Impact on overall survival of radiactive iodine low-risk differentiated thyroid cancer patients. J Clin Endocrinol Metab. 2012;97:1526-1535.

36. Mallick U, Harmer C, Yap B, Wadsley J, Clarke S, Moss L, et al. Ablation with low-dose radioiodine and thyrotropin alfa in thyroid cancer. $\mathrm{N}$ Engl J Med. 2012;366:1674-1685

37. Cheng W, Ma C, Fu H, Li J, Chen S, Wu S, et al. Low- or high-dose radioiodine remnant ablation for differentiated thyroid carcinoma: a meta-analysis. J Clin Endocrinol Metab. 2013;98:1353-1360

38. Fallahi B, Beiki D, Takavar A, Fard-Esfahani A, Gilani KA, Saghari M, et al. Low versus high radioiodine dose in postoperative ablation of residual thyroid tissue in patients with differentiated thyroid carcinoma: a large randomized clinical trial. Nucl Med Commun. 2012;33:275-282.

39. Shah MD, Hall FT, Eski SJ, Witterick IJ, Walfish PG, Freeman JL. Clinical course of thyroid carcinoma after neck dissection. Laryngoscope. 2003;113:2102-2107.

40. Ruel E, Thomas S, Dinan M, Perkins JM, Roman SA, Sosa JA. Adjuvant radiactive iodine therapy is associated with improved survival for patients with intermediate-risk papillary thyroid cancer. J Clin Endocrinol Metab. 2015,100:1529-1536.

41. Lamartina L, Durante C, Filetti S, Cooper DS. Low-risk differentiated thyroid cancer and radioiodine remnant ablation: a systematic review of the literature. J Clin Endocrinol Metab. 2015;100:1748-1761.

42. Sabra M, Grewal RK, Ghossein RM, Tuttle RM. Higher administered activities of radiactive iodine are associated with less structural persistent response in older, but not younger, papillary thyroid cancer patients with lateral neck lymph node metastases. Thyroid. 2014;24: 1088-1095.

43. Schlumberger M, Tubiana M, De-Vathaire F, Hill C, Gardet P, Travagli JP, et al. Long-term results of treatment of 283 patients with lung and bone metastases from differentiated thyroid carcinoma. J Clin Endocrinol Metab. 1986:63:960-967

44. Van-Nostrand D, Atkins F, Yeganeh F, Acio E, Bursaw R, Wartofsky L. Dosimetrically determined doses of radioiodine for the treatment of metastatic thyroid carcinoma. Thyroid. 2002:12:121-134.

45. Beckers C, Van-Ypersele-De-Strihou C, Coche E, Troch R, Malvaux P. lodine metabolism in severe renal insufficiency. J Clin Endocrinol Metab. 1969;29:293-296.

46. Tuttle M, Lebeauf R, Robbins RJ, Qualey R, Pentlow K, Larson SM, et al. Empiric radiactive iodine dosing regimens frequently exceed maximum tolerated activity levels in elderly patients with thyroid cancer. $\int \mathrm{Nucl}$ Med. 2006:47:1587-1591

47. Avram AC. Radioiodine scintigraphy with SPECT/CT: an important diagnostic tool for thyroid cancer staging and risk stratification. J Nucl Med. 2012;53:754-764.

48. Avram AM, Doherty GM, Fig LM, Wong K. Diagnostic 131-I fusion SPECT-CT Imaging in postoperative thyroid cancer patients: what is the impact on staging? Thyroid. 2011;21:193

49. Brenner W. Is thyroid stunning a real phenomenon or just fiction? J Nucl Med. 2002;43:835-836

50. Guiraud-Vitaux F, Feldmann G, Vadrot N, Charles-Gupta S, Durand-Schneider AM, Colas-Linhart N, et al. Early ultrastructural injuries in the thyroid of the normal rat radioinduced by diagnostic and/or therapeutic amounts of iodine-131. Cell Mol Biol (Noisy-le-grand). 2001; 47:495-502.

51. Kao CH, Yen TC. Stunning effects after a diagnostic dose of iodine-131. Nuklearmedizin. 1998;37:30-32.

52. Aide N, Heutte N, Rame JP, Rousseau E, Loiseau C, Henry-Amar M, et al. Clinical relevance of single-photon emission computed tomography/ computed tomography of the neck and thorax in postablation 131I scintigraphy for thyroid cancer. J Clin Endocrinol Metab. 2009;94: 2075-2084.

53. Ciappuccini R, Heutte N, Trzepla G, Rame JP, Vaur D, Aide N, et al. Postablation (131)I scintigraphy with neck and thorax SPECT-CT and stimulated serum thyroglobulin level predict the outcome of patients with differentiated thyroid cancer. Eur J Endocrinol. 2011:164:961-969.

54. Tuttle RM, Tala H, Shah J, Leboeuf R, Ghossein R, Gonen M, et al. Estimating risk of recurrence in differentiated thyroid cancer after total thyroidectomy and radiactive iodine remnant ablation: using response to therapy variables to modify the initial risk estimates predicted by the new American Thyroid Association staging system. Thyroid. 2010;20: $1341-1349$ 
55. Vaisman F, Shaha A, Fish S, Tuttle RM. Initial therapy with either thyroid lobectomy or total thyroidectomy without radiactive iodine remnant ablation is associated with very low rates of structural disease recurrence in properly selected patients with differentiated thyroid cancer. Clin Endocrinol (Oxf). 2011;75:112-119.

56. Webb RC, Howard RS, Stojadinovic A, Gaitonde DY, Wallace MK Ahmed $\mathrm{J}$, et al. The utility of serum thyroglobulin measurement at the time of remnant ablation for predicting disease-free status in patients with differentiated thyroid cancer: a metaanalysis involving 3947 patients. $\mathrm{J}$ Clin Endocrinol Metab. 2012;97:2754-2763.

57. Latrofa F, Ricci D, Montanelli L, Rocchi R, Piaggi P, Sisti E, et al. Lymphocytic thyroiditis on histology correlates with serum thyroglobulin autoantibodies in patients with papillary thyroid carcinoma: impact on detection of serum thyroglobulin. J Clin Endocrinol Metab. 2012;97:2380-2387.

58. Görges R, Maniecki M, Jentzen W, Sheu SN, Mann K, Bockisch A, et al. Development and clinical impact of thyroglobulin antibodies in patients with differentiated thyroid carcinoma during the first 3 years after thyroidectomy. Eur J Endocrinol. 2005;153:49-55.

59. Spencer CA. Clinical review: clinical utility of thyroglobulin antibody (TgAb) measurements for patients with differentiated thyroid cancers (DTC). J Clin Endocrinol Metab. 2011;96:3615-3627.

60. Kim WG, Yoon JH, Kim WB, Kim TY, Kim EY, Kim JM, et al. Change of serum antithyroglobulin antibody levels is useful for prediction of clinica recurrence in thyroglobulin-negative patients with differentiated thyroid carcinoma. J Clin Endocrinol Metab. 2008:93:4683-4689.

61. Palaniswamy SS, Subramanyam P. Diagnostic utility of PETCT in thyroid malignancies: an update. Ann Nucl Med. 2013;27:681-693.

62. Feine U, Lietzenmayer R, Hanke JP, Held J, Wöhrle H, Müller-Schauenburg W. Fluorine-18-FDG and iodine-131-iodide uptake in thyroid cancer. J Nucl Med. 1996;37:1468-1472.
63. Schönberger J, Rüschoff J, Grimm D, Marienhagen J, Rümmele $P$, Meyringer R, et al. Glucose transporter 1 gene expression is related to thyroid neoplasms with an unfavorable prognosis: an immunohistochemical study. Thyroid. 2002;12:747-754

64. Salvatori M, Biondi B, Rufini V. Imaging in endocrinology: 2-[18F]-fluoro-2-deoxy-D-glucose positron emission tomography/computed tomography in differentiated thyroid carcinoma: clinical indications and controversies in diagnosis and follow-up. Eur J Endocrinol. 2016; 173:115-130.

65. Pacak K, Eisenhofer G, Goldstein DS. Functional imaging of endocrine tumors: role of positron emission tomography. Endoc Rev. 2004:25:568-580.

66. Wang W, Larson SM, Fazzari M, Tickoo SK, Kolbert K, Sgouros G, et al. Prognostic value of [18F]fluorodeoxyglucose positron emission tomographic scanning in patients with thyroid cancer. J Clin Endocrinol Metab. 2000;85:1107-1113.

67. Leboulleux S, Schroeder PR, Schlumberger M, Ladenson PW. The role of PET in follow-up of patients treated for differentiated epithelial thyroid cancers. Nat Clin Pract Endocrinol Metab. 2007;3:112-121.

68. Grabellus F, Worm K, Schmid KW, Sheu SY. The BRAFV600E mutation in papillary thyroid carcinoma is associated with glucose transporter 1 overexpression. Thyroid. 2012;22:377-382.

69. Xing M, Alzahrani AS, Carson KA, Viola D, Elisei R, Bendlova B, et al. Association between BRAF V600E mutation and mortality in patients with papillary thyroid cancer. JAMA. 2013;309:1493-1501.

70. Nagarajah J, Ho AL, Tuttle RM, Weber WA, Grewal RK, et al. Correlation of BRAFV600E mutation and glucose metabolism in thyroid cancer patients: an 18F-FDG PET study. J Nucl Med. 2015;56:662-666.

71. Stokkel MP, Duchateau CS, Drogoiescu C. The value of FDG-PET in the follow-up of differentiated thyroid cancer: a review of the literature. $Q J$ Nucl Med Mol Imaging. 2006;50:78-87. 